\title{
EDITORIAL
}

\section{Turning tragedy into triumph}

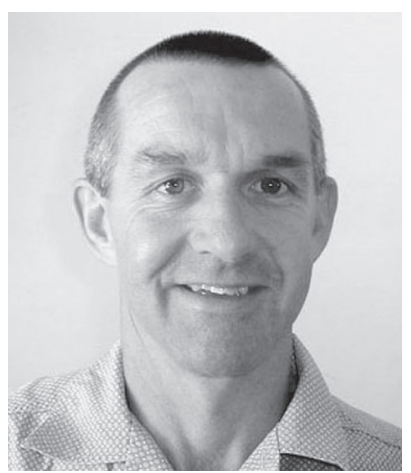

I have just finished reading a book titled Samaritan of South African Rugby, written by Pat Tebbutt. It is an historical account of the Chris Burger/Petro Jackson Players' Fund which was established to support rugby players who have sustained serious injuries. The story starts in August 1980, the day Western Province played the Free State in Bloemfontein. Following a robust loose scrum, all the players involved got to their feet except Chris Burger of Western Province, who lay motionless on the ground with a broken neck. By 4 am the following morning he had died. This tragic event inspired his colleagues, led by the Western Province captain Morné du Plessis, to create the Chris Burger Players' Fund to raise money to support injured players. Thirty years later over 400 seriously injured players have been assisted by the fund at a cost of more than 30 million rand.

As the fund evolved, and the ethos for making rugby safer grew there was need to actively promote an injury prevention programme designed to lower the risk of injury. Rather than re-invent the wheel, the leaders of the successful Rugbysmart programme in New Zealand and Smartrugby programme in Australia were consulted. Both these programmes were designed to achieve the goals of making rugby safer. As a result BokSmart was launched. BokSmart adopted the principles of these two existing programmes and then customised the content to serve the needs of South African rugby. The programme has grown exponentially. Since the inception of BokSmart in mid2009, over 10000 coaches have been trained in principles of safe rugby. In addition, BokSmart has established a website rich with evidence-based information on matters pertaining to rugby (www. boksmart.com). Topics range from physical preparation for rugby to the on-field management of serious injuries. All articles are freely available and are designed to serve and educate anyone involved in rugby.

This preamble brings me to the link to this edition of the journal. BokSmart commissioned the review paper on concussion, written by $\mathrm{Dr}$ Jon Patricios - this review provides the most current best practice principles for managing concussion. The paper explains how a series of international consensus statements, which started in 2001, accelerated the understanding of the management of this injury. While there is still much to learn, the field has progressed significantly in the last decade.

The remainder of the journal has an assortment of interesting papers. For example, a study on scuba diving describes how divers neglect their auditory systems. The study shows that there needs to be more education on ear problems following a dive, as divers do not generally have sufficient knowledge to manage the conditions properly.

Then there is a case study on the Paget-Schroetter syndrome, followed by a short review of the topic. Although not a common condition it has the potential to be serious and if detected early and managed properly can reduce the recovery time significantly.

Next there is an interesting paper on the most common physica therapy modalities for the treatment of whiplash. The paper shows that there is no standard treatment and recommends the establishment of a best practice protocol.

The 'Editor's choice' paper, published with permission from the British Journal of Sports Medicine, describes a novel test which has the potential to detect symptoms of overreaching and overtraining. Although further research needs to be done, this test is innovative and has the potential to be practical in managing high-performance athletes.

As this is the last edition of the South African Journal of Sports Medicine for 2010 it is appropriate to thank all the people that make this journal possible. Firstly, the reviewers should get applauded. They generally do an excellent job, with no recognition or reward. It is a time-consuming and difficult task. I know some of the authors get frustrated at the detailed reviews, but the quality of paper that finally gets accepted for publication is always much better than the original form of the paper. Next, the staff of the Health and Medical Publishing Group are thanked. Their efficient, friendly service makes the job of this editor much easier to manage!

\section{Mike Lambert}

Editor-in-Chief 